Check for updates

London, UK

Cite this as: BMJ 2021;373:n1596 http://dx.doi.org/10.1136/bmj.n1596 Published: 21 June 2021

\title{
Covid-19: Cases of delta variant rise by $79 \%$, but rate of growth slows
}

\section{Adrian O'Dowd}

Almost all new cases of covid-19 are the delta variant but new data suggests that while case numbers are increasing, the rate of growth is slower than a week ago.

Public Health England's weekly covid-19 variant cases data ${ }^{1}$ show that numbers of the delta variant in the UK have risen by 33630 since last week to a total of 75 953, a $79 \%$ increase. The most recent data show $99 \%$ of sequenced and genotyped cases across the country are the delta variant.

The data also show that 58830 positive test results were recorded between 11 and 17 June which represents an increase of $33.7 \%$ on the previous seven days.

Public Health England said that the data showed there was a higher risk of hospital admission for patients with the delta variant compared with the alpha variant, but its analysis ${ }^{2}$ revealed that two doses of vaccine gave a high degree of protection against hospital admission, estimated to be more than $90 \%$.

According to the agency's latest variant technical briefing, ${ }^{3}$ as of 14 June a total of 806 people had been admitted to hospital with the delta variant of the virus-an increase of 423 since last week. Among these cases, 527 people were unvaccinated and only 84 of the 806 had received both doses.

Jenny Harries, chief executive of the UK Health Security Agency, said, "Cases are rising rapidly across the country and the delta variant is now dominant. The increase is primarily in younger age groups, a large proportion of which were unvaccinated but are now being invited to receive the vaccine. It is encouraging to see that hospital admissions and deaths are not rising at the same rate, but we will continue to monitor it closely."

Independent SAGE, a group of scientists who provide independent scientific advice to the UK government and public, said it was encouraged by the success of the vaccine programme, but stressed the need for mitigation measures to help stop the spread of the virus.

In the report ${ }^{4}$ outlining the measures that the government should continue to provide, Independent SAGE chair David King said, "While it is quite right to propose that people get vaccinated, tested, and observe covid safeguards, it is quite wrong to suggest that they do so on their own.

"So, while the lifting of restrictions may lead to an increased emphasis on the public appraising and responding to risks, this cannot work if the government fails to provide (or worse, removes) the forms of support that are necessary for members of the public 'to do the right thing'."
The group said the government must continue to provide vaccination centres in easily accessible places, fully paid time off work to allow people to get vaccinated, and full pay and support packages for people asked to self-isolate.

Paul Hunter, professor in medicine at University of East Anglia, said, "Although it is still a little too early to be sure, the rate of growth in the epidemic in the UK seems to have slowed somewhat in the past few days.

"Cases of covid are still rising but apparently not as rapidly as they were a week ago. On balance, it does appear that the epidemic in the UK may no longer be increasing exponentially.”

1 Public Health England. Variants: distribution of case data, 11 June 2021. 18 June2021. www.gov.uk/government/publications/covid-19-variants-genomically-confirmed-case-numbers/variants-distribution-of-case-data-18-june2021.

2 Public Health England. Effectiveness of covid-19 vaccines against hospital admission with the Delta (B.1.617.2) variant. 14 June 2021. https://khub.net/web/phe-national/public-library///document_library/v2WsRK3ZIEig/view/479607266.

3 Public Health England. Investigation of SARS-CoV-2 variants of concern: technical briefings. 18 June 2021. www.gov.uk/government/publications/investigation-of-novel-sars-cov-2-variant-variant-of-concern-20201201.

4 Independent SAGE. The Independent Sage Report 44: Continuing need for support measures. 18 June 2021. www.independentsage.org/wp-content/uploads/2021/06/Supprt-document-final.pdf.

This article is made freely available for use in accordance with BMJ's website terms and conditions for the duration of the covid-19 pandemic or until otherwise determined by BMJ. You may use, download and print the article for any lawful, non-commercial purpose (including text and data mining) provided that all copyright notices and trade marks are retained. 